\title{
Vanadium sorption by mineral soils: development of a predictive
}

model

Maja A. Larsson ${ }^{\mathrm{a}}$, Golshid Hadialhejazi ${ }^{\mathrm{b}}$, Jon Petter Gustafsson ${ }^{\mathrm{a}, \mathrm{b}, *}$

${ }^{\text {a } D e p a r t m e n t ~ o f ~ S o i l ~ a n d ~ E n v i r o n m e n t, ~ S w e d i s h ~ U n i v e r s i t y ~ o f ~ A g r i c u l t u r a l ~ S c i e n c e s, ~ B o x ~ 7014, ~} 75007$ Uppsala, Sweden

${ }^{\mathrm{b}}$ Division of Land and Water Resources Engineering, KTH Royal Institute of Technology, Teknikringen 76, 100 44 Stockholm, Sweden

Corresponding author:

E-mail address: jon-petter.gustafsson@slu.se (J.P. Gustafsson) 


\begin{abstract}
The toxicity of vanadium in soils depends on its sorption to soil components. Here we studied the vanadate $(\mathrm{V})$ sorption properties of 26 mineral soils. The data were used to optimise parameters for a Freundlich equation with a $\mathrm{pH}$ term. Vanadium K-edge XANES spectroscopy for three selected soils confirmed that the added vanadate(V) had accumulated mostly as adsorbed vanadate(V) on Fe and Al hydrous oxides, with only minor contributions from organically complexed vanadium(IV). Data on $\mathrm{pH}$-dependent V solubility for seven soils showed that on average $0.36 \mathrm{H}^{+}$accompanied each $\mathrm{V}$ during adsorption and desorption. The resulting model provided reasonable fits to the $\mathrm{V}$ sorption data, with $r^{2}>0.99$ for 20 of 26 soils. The observed $K_{\mathrm{dS}}$ value, i.e. the ratio of total to dissolved V, was strongly dependent on $\mathrm{V}$ addition and soil; it varied between 3 and 4 orders of magnitude. The model was used to calculate the Freundlich sorption strength (FSS), i.e. the amount of V sorbed at $[\mathrm{V}]=2.5 \mathrm{mg}$ $\mathrm{L}^{-1}$, in the concentration range of observed plant toxicities. A close relationship between FSS and oxalate-extractable $\mathrm{Fe}$ and $\mathrm{Al}$ was found $\left(r^{2}=0.85\right)$ when one acidic soil was removed from the regression. The FSS varied between 27 and $8718 \mathrm{mg} \mathrm{V} \mathrm{kg}^{-1}$, showing that the current environmental guidelines can be both under- and overprotective for vanadium.
\end{abstract}

Keywords: vanadate, Freundlich, hydrous oxides, $\mathrm{pH}$ dependence, speciation 


\section{Introduction}

Vanadium is a metal used in steel production, and therefore by-products (slags etc.) from the steel industry can be elevated in vanadium. In European soils, the median pseudo-total vanadium concentration (i.e. vanadium extracted by aqua regia) is $60.4 \mathrm{mg} \mathrm{kg}^{-1}$, with a range from 1.28 to $537 \mathrm{mg} \mathrm{kg}^{-1}$, according to the FOREGS database (Salminen et al. 2005). In many soils, only a very small part of the total V is easily leached (Cappuyns and Slabbinck, 2012; Cappuyns and Swennen, 2014).

Relatively little is known about the speciation of $\mathrm{V}$ in soils. The geochemically active soil vanadium is generally expected to be present either as vanadium(IV) or as vanadium(V). The former occurs mainly as the oxocation $\mathrm{VO}^{2+}$ (vanadyl), whereas vanadium(V) exists as the oxyanions $\mathrm{H}_{2} \mathrm{VO}_{4}{ }^{-}$or as $\mathrm{HVO}_{4}{ }^{2-}$ (collectively referred to as vanadate) depending on the $\mathrm{pH}$ value. Vanadate(V) is considered the most toxic vanadium species (Martin and Kaplan, 1998; Larsson et al. 2013). In three Swedish soils it was found that the soil appears to be dominated by vanadium(IV) bound in primary minerals (Larsson et al. 2015a; Larsson et al. 2015b); this V has probably a low bioavailability. However, when vanadium is added to soils (either as vanadium(IV) or vanadium(V) salts), it tends to accumulate as vanadate(V) sorbed to iron and aluminium hydrous oxides, except in acid organic soils, in which vanadyl(IV) complexed to organic matter will predominate (Larsson et al. 2015a, Larsson et al. 2015b).

The sorption of vanadate(V) to iron(III) hydrous oxides is strong and involves the formation of inner-sphere bidentate complexes (Peacock and Sherman, 2004). As expected for anion adsorption, vanadate $(\mathrm{V})$ is adsorbed most strongly at low $\mathrm{pH}$, although some adsorption occurs at $\mathrm{pH}$ values as high as 10-11, against electrostatic repulsion (Blackmore et al. 1996). The values of the surface complexation constants, as well as results from competition 
experiments, show that vanadate $(\mathrm{V})$ is bound even more strongly than phosphate and arsenate on Fe hydrous oxides (Rietra, 2001; Brinza et al. 2008; Wällstedt et al. 2010). The role of Al hydrous oxides for vanadate(V) sorption is less well known, although results from vanadium K-edge XANES experiments show that they contribute significantly to adsorption (Burke et al. 2012; Larsson et al. 2015a).

Vanadium is toxic to plants at high doses. For the most sensitive plants, toxic effects start to appear at solution concentrations of $1 \mathrm{mg} \mathrm{L}^{-1}$ (Kaplan et al. 1990; Larsson et al. 2013). The amount of $\mathrm{V}$ that can be added to a soil without giving toxic effects is, however, strongly dependent on the extent of vanadium sorption (Baken et al. 2012; Larsson et al. 2013). For these reasons it is of interest to develop models that can predict vanadium sorption to soils.

There are different approaches to the development of models for simulation of metal binding in soils. One is to use process-oriented surface complexation models (Gustafsson, 2006; Dijkstra et al. 2009; Weng et al. 2011). However, although these models provide insights to the mechanisms involved, they are difficult to set up for soils due to the large number of parameters that need to be estimated. Another approach is to use empirical isotherm equations. Although they are not process-oriented they can still be useful for predicting anion sorption as they require less input. For vanadium, the use of empirical partition relations (Groenenberg et al. 2012) and of an extended Freundlich equation (Gäbler et al. 2009) were tested, with promising results. The Freundlich model can also be extended with a term accounting for the influence of $\mathrm{pH}$, which is often the most important parameter that governs metal sorption in soils (Sauvé et al. 2000). We recently showed a new way to include such a $\mathrm{pH}$ term for describing $\mathrm{SO}_{4}$ adsorption to soils (Gustafsson et al. 2015). An important prerequisite for the use of a Freundlich model is that only one type of adsorption process is 
important. In the case of vanadium, the model is not likely to perform well if both vanadium(IV) complexation to organic matter and vanadate(V) sorption to $\mathrm{Fe}$ and $\mathrm{Al}$ hydrous oxides are significant. Therefore it may be hypothesized that the Freundlich models may work in mineral soils in which vanadate(V) sorption may be the predominant process.

The objective of this paper is to investigate the use of the $\mathrm{pH}$-dependent Freundlich model of Gustafsson et al. (2015) for describing vanadate(V) sorption to 26 mineral soils (all having less than $12 \%$ organic $\mathrm{C}$ ), and to discuss the possible use of the model for risk assessments. To investigate the hypothesis that adsorbed vanadate $(\mathrm{V})$ was the predominant reaction product, vanadium K-edge XANES spectroscopy was performed for three of the soils, which were different concerning $\mathrm{pH}$, content of $\mathrm{Fe}$ and $\mathrm{Al}$ hydrous oxides, and texture.

\section{Materials and Methods}

\subsection{Soils}

A total of 26 samples from different mineral soils in Sweden, Belgium and Spain were used for the batch experiment. These soils represent a wide variation in soil properties and land management. Most of the soils were non-calcareous, with the exceptions of Fors and Guadalajara. Selected soil properties are shown in Table A1 (Associated content). Most of the soil samples were from A horizons (topsoils). Some of the samples were from spodic B horizons of Spodosols (Kloten, Risbergshöjden, Risfallet and Tärnsjö). A C horizon from the Kloten Spodosol was also included. To study the effect of phosphate, A horizon samples from the Kungsängen fertility experiment were used; these samples are described in more detail by Eriksson et al. $(2015,2016)$. Briefly, the A3 treatment of the Kungsängen soil received no P fertilizer since 1963, whereas the D3 treatment received replacement of $\mathrm{P}$ with the previous year's harvest plus an additional $20 \mathrm{P} \mathrm{kg} \mathrm{ha}^{-1}$ and $50 \mathrm{~kg} \mathrm{~K} \mathrm{ha}^{-1}$. The concentration of acid 
ammonium lactate-extractable $\mathrm{P}(\mathrm{P}-\mathrm{AL})$ was $1.0 \mathrm{mmol} \mathrm{P} \mathrm{kg}-1$ in the $\mathrm{A} 3$ and $2.9 \mathrm{mmol} \mathrm{P} \mathrm{kg}^{-1}$ in the D3 treatment, respectively (Eriksson et al., 2016). After collection, the samples were air-dried and sieved ( $2 \mathrm{~mm})$ prior to the batch experiments.

\subsection{Batch experiments}

In the batch experiments, $2 \mathrm{~g}$ air-dried soil was mixed with $30 \mathrm{~mL}$ solution in a polypropylene centrifuge tube with a screw cap. The solution added to the soil always contained $0.01 \mathrm{M}$ $\mathrm{NaNO}_{3}$. For all soils, different concentrations of vanadate(V) (added as dissolved $\mathrm{NaVO}_{3}$ ) were added to study vanadate(V) sorption as a function of the equilibrium vanadium concentration in solution. The additions corresponded to $0,0.15,0.3,0.6,1.05,1.5,2.25,3$ and 4.5 mmol V kg${ }^{-1}$ dry soil. For seven soils (Guadalajara, Kungsängen A3, Kungsängen D3, Pustnäs, Säby, Ter Munck, Zwijnaarde), pH-dependent V sorption was studied. In these experiments, varying concentrations of acid $\left(\right.$ as $\left.\mathrm{HNO}_{3}\right)$ or base (as $\mathrm{NaOH}$ ) was added to different centrifuge tubes to produce a range of $\mathrm{pH}$ values. These soil suspensions also contained $150 \mu \mathrm{M}$ added vanadate(V) (equivalent to $2.25 \mathrm{mmol} \mathrm{V} \mathrm{kg}^{-1}$ or $115 \mathrm{mg} \mathrm{V} \mathrm{kg}^{-1}$ ) as well as $0.01 \mathrm{M} \mathrm{NaNO}_{3}$. Further, the influence of competing $\mathrm{PO}_{4}-\mathrm{P}\left(\right.$ as $\mathrm{NaH}_{2} \mathrm{PO}_{4}$ ) was studied in a separate series that, in addition to the concentrations of $\mathrm{V}$ and $\mathrm{NaNO}_{3}$ given above, also contained $150 \mu \mathrm{M}$ added $\mathrm{PO}_{4}-\mathrm{P}$ (equivalent to $2.25 \mathrm{mmol} \mathrm{P} \mathrm{kg}^{-1}$ ).

After 6 days of gentle shaking at room temperature, the suspension was centrifuged. The $\mathrm{pH}$ of the supernatant was measured with a Radiometer combination glass electrode. The remaining supernatant solution was filtered through a $0.2 \mu \mathrm{m}$ single-use filter (Acrodisc PF) and acidified to $1 \% \mathrm{HNO}_{3}$ (suprapur) prior to the analysis of $\mathrm{PO}_{4}-\mathrm{P}$ (colorimetrically using a Tecator Aquatec 5400 spectrophotometer with flow injection analysis), and of V, Al, Ca, Fe and $\mathrm{Mg}$ (ICP-SFMS at a quality-accredited laboratory; only the V results are shown). 


\subsection{XANES spectroscopy}

By means of vanadium K-edge XANES spectroscopy, the speciation of vanadium was investigated for three selected soils from the batch experiments: Pustnäs A, Säby A, and Risbergshöjden Bs2 (c.f. Table 1). Unamended soil samples as well as samples treated with $2.25 \mathrm{mmol} \mathrm{kg}^{-1}$ vanadate( $\left.\mathrm{V}\right)$ (i.e. $115 \mathrm{mg} \mathrm{V} \mathrm{kg}^{-1}$ ) were used. The former samples were used in their air-dried state, whereas the latter were recovered from centrifuged soil suspensions after the batch experiments described in section 2.1. The samples were left to air-dry to reduce the water content, but they were not allowed to dry out completely.

Vanadium K-edge XANES data were collected at beamline 4-3 at the Stanford Synchrotron Radiation Lightsource (SSRL), Stanford, USA. The spectra for Pustnäs A and Säby A have been reported elsewhere (Larsson et al. 2015b), but here we give further details on linear combination fitting results. Procedures for collecting spectra of standards (V oxides, vanadate(V) adsorbed to ferrihydrite, vanadyl(IV) complexed to organic matter, etc) are detailed in Larsson et al. (2015a). Beamline 4-3 was equipped with a Si[111] double crystal monochromator, and it operated at $3.0 \mathrm{GeV}$ with a current of $97-100 \mathrm{~mA}$. All measurements were performed in fluorescence mode using a 13-element Ge array fluorescence detector. The energy was calibrated at the vanadium K edge at $5465 \mathrm{eV}$ (Thompson et al. 2009) using V foil. All samples were measured over an energy range from 5235 to $5645 \mathrm{eV}$ with an experimental resolution of $\pm 0.5 \mathrm{eV}$. The energy step size was $10 \mathrm{eV}$ between 5235 and 5450 $\mathrm{eV}, 0.2 \mathrm{eV}$ between 5450 and $5510 \mathrm{eV}$, and $1 \mathrm{eV}$ between 5510 and $5665 \mathrm{eV}$. Usually, two or three scans were collected for each sample. 
The XANES data were processed with Athena, version 0.9.24 (Ravel and Newville, 2005), using well established methods (Kelly et al. 2008). Multiple spectra were merged and normalized during which a linear baseline function was subtracted from the spectral region below the edge (between -50 to $-20 \mathrm{eV}$ relative to $\mathrm{E}_{0}$ ). A quadratic function was used to normalize spectra across the post-white-line region between 16 and $140 \mathrm{eV}$ relative to $\mathrm{E}_{0}$ taken as the maximum in the first-derivative spectrum for vanadium foil $(5465 \mathrm{eV})$.

Linear combination fitting (LCF) (Tannazi and Bunker, 2005) of vanadium-treated samples was performed using weighted combinations of spectra from the following 4 standards: vanadium(V) adsorbed to ferrihydrite, vanadium(V) adsorbed to aluminium hydroxide, vanadyl(IV) complexed to mor layer material (O horizon from a Spodosol), and the spectrum from the unamended soil samples. For the latter samples, which contained mostly vanadium(IV) (Larsson et al. 2015b), it was not possible to obtain a good linear combination fit using any combination of the vanadium(IV) standards analysed (vanadium(IV) complexed to mor, aqueous vanadyl(IV), and $\mathrm{V}_{2} \mathrm{O}_{4}(\mathrm{~s})$ ), probably because none of these were representative for the vanadium occurring in the samples. In the fitting procedure, no energy shifts were permitted. The fitting range was constrained to between -10 to $50 \mathrm{eV}$ relative to $\mathrm{E}_{0}$. A standard was included in the fit only if it contributed to an improved goodness-of-fit ( $R$ value) according to Athena. Moreover, fits were accepted only in cases when the weighting fractions summed to $100 \pm 10 \%$, and fractions were re-normalized to a sum of $100 \%$.

\subsection{Modelling}

We used the extended Freundlich equation of Gustafsson et al. (2015), which was originally used for $\mathrm{SO}_{4}$ adsorption onto forest soils. For vanadium, this equation can be written as:

$Q=K_{\mathrm{F}} \cdot\left([\mathrm{V}] \cdot\left\{\mathrm{H}^{+}\right\}^{\eta}\right)^{m}$ 
where $Q$ is the amount of adsorbed $\mathrm{V}\left(\mathrm{mol} \mathrm{kg}{ }^{-1}\right.$ dry soil) and [V] is the total dissolved concentration of $\mathrm{V}\left(\mathrm{mol} \mathrm{L}^{-1}\right) . K_{\mathrm{F}}, m$ and $\eta$ are adjustable parameters where $K_{\mathrm{F}}$ is termed the Freundlich coefficient while $m$ and $\eta$ are non-ideality coefficients. This equation is slightly different from the conventional form of the extended Freundlich equation as it assumes that the ratio of the non-ideality coefficients for $\mathrm{V}$ and $\mathrm{H}^{+}$is fixed by the so-called proton coadsorption stoichiometry $\eta$ (Gustafsson et al. 2015). As we did not include any acid organic soils, an initial assumption was that the sorbed and dissolved vanadium was dominated by vanadate $(\mathrm{V})$. If so, and if the $\mathrm{pH}$ value is between $\mathrm{pH} 3.5$ and $\mathrm{pH} 8.8$ (being the stability range of $\mathrm{H}_{2} \mathrm{VO}_{4}{ }^{-}$at room temperature), the $\eta$ coefficient can be interpreted as the number of $\mathrm{H}^{+}$ions that follow each $\mathrm{H}_{2} \mathrm{VO}_{4}{ }^{-}$ion during adsorption and desorption. After taking the logarithm of both sides, and substituting $\log \left\{\mathrm{H}^{+}\right\}$for $\mathrm{pH}$, we obtain:

$\log Q=\log K_{\mathrm{F}}+m \cdot(\log [\mathrm{V}]-\eta \cdot \mathrm{pH})$

It follows that a plot of $\log Q$ vs. $\log [\mathrm{V}]-\eta \cdot \mathrm{pH}$ should lead to a straight line with the slope $m$ and the intercept $K_{\mathrm{F}}$. Further it should be noted that $Q$ can be broken up into two parts:

$Q=Q_{\text {sorb }}+Q_{\text {ini }}$

where $Q_{\text {sorb }}$ is the amount of V sorbed during the experiment, whereas $Q_{\text {ini }}$ is the amount of V initially sorbed in the soil. The value of $Q_{\text {ini }}$ is not known. In principle, it can be estimated from extraction. However, it is not currently known what extractant that best targets the amount of adsorbed V (c.f. Gäbler et al. 2009). For this reason, we treated $Q_{\text {ini }}$ as an adjustable 
parameter. Equation 2 then contains four adjustable parameters, which can be brought down to three using a common value of $\eta$. Hence, the calibration of the model followed these steps:

1. For each of the seven soil samples for which $\mathrm{pH}$-dependent vanadium sorption data existed (the series with no $\mathrm{P}$ added was used), all four adjustable parameters of the model were optimized. This was done using linear regression of $\log Q$ vs. $\log \left[\mathrm{VO}_{4}{ }^{2-}\right]-$ $\eta \cdot \mathrm{pH}$ with the trendline tool in Microsoft Excel, and by systematically change the values of $Q_{\text {ini }}$ and $\eta$ until the best fit was obtained, as judged from linear regression between modelled vs. measured $\log Q_{\text {sorb. }}$. A common value of $\eta$ was then found by averaging the optimized $\eta$ values from the seven series.

2. The model was then optimized for all 26 soils by repeating the procedure described above, but now with a fixed $\eta$.
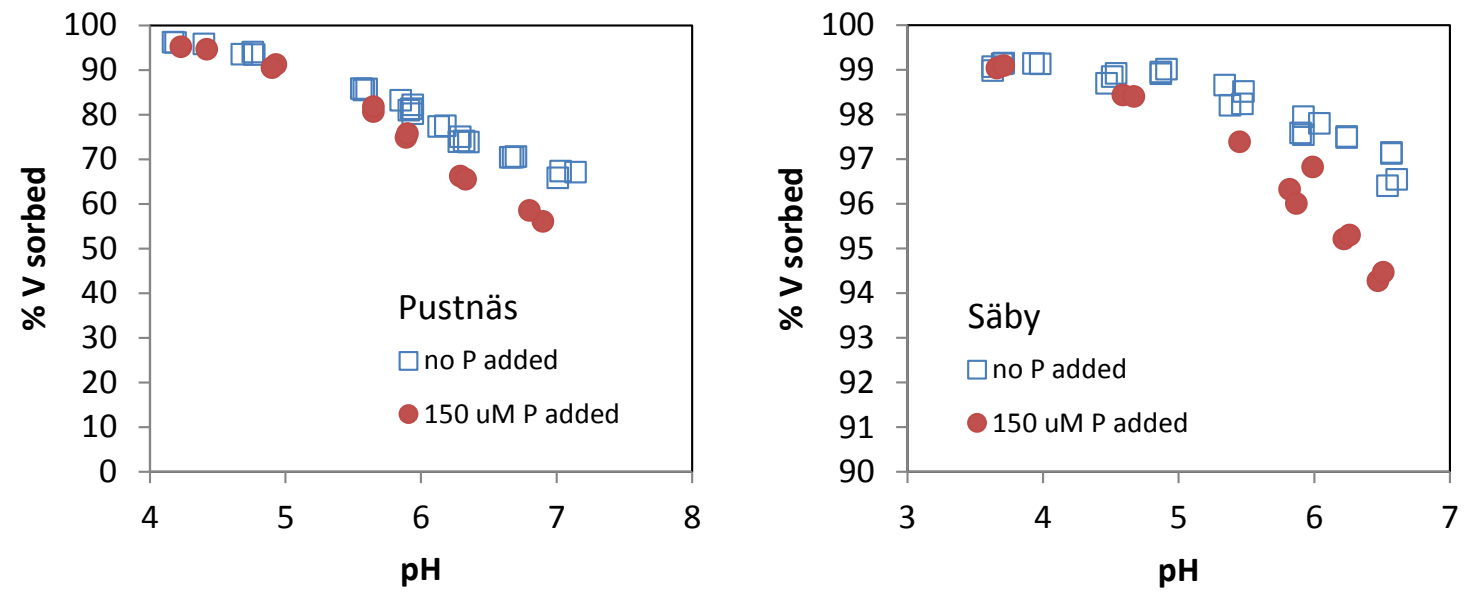

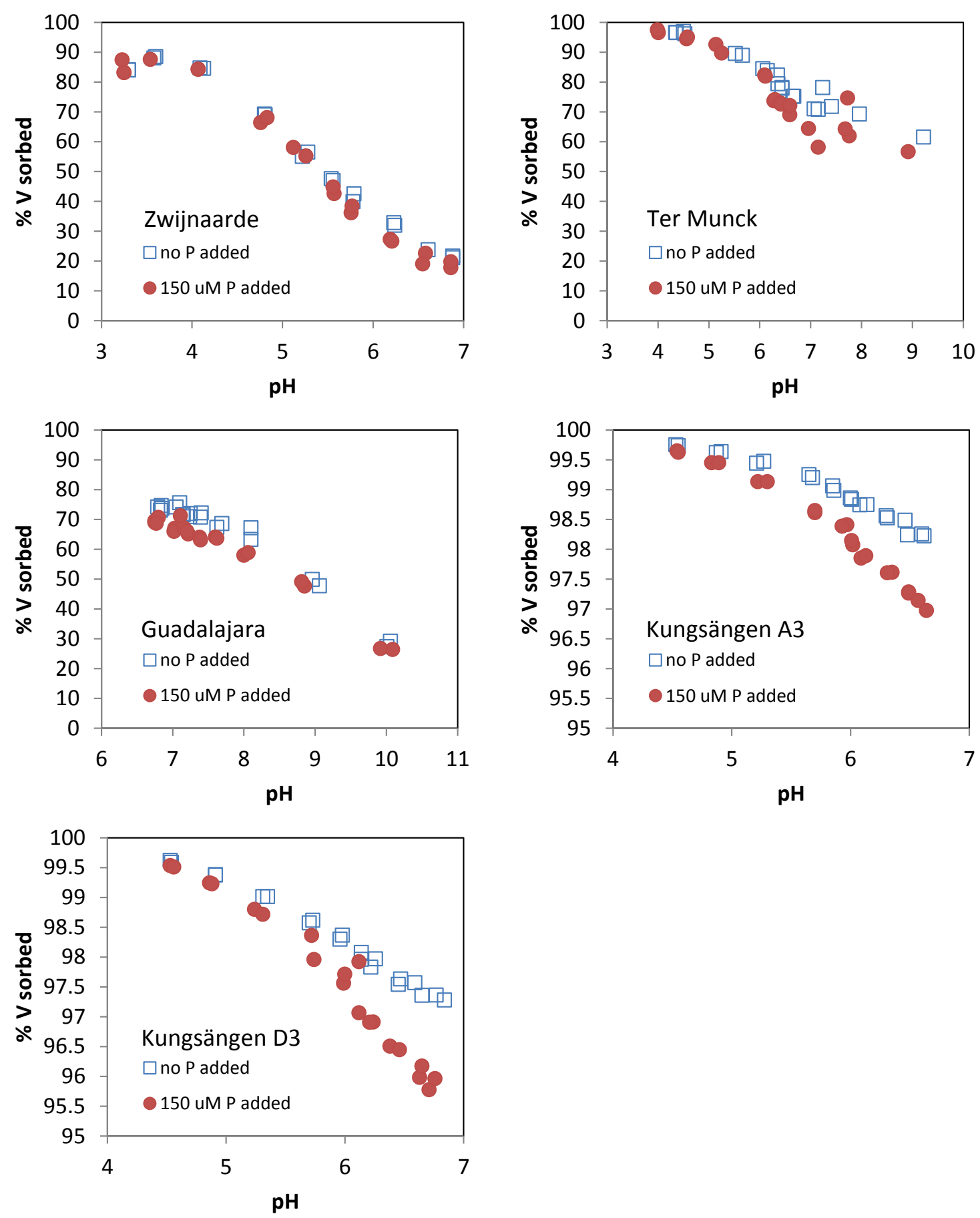

Fig. 1. Sorbed vanadium as a function of $\mathrm{pH}$ in soil suspensions from seven different soils, after the addition of $2.25 \mathrm{mmol} \mathrm{kg}{ }^{-1}$ vanadate(V) in $0.01 \mathrm{M} \mathrm{NaNO}_{3}$. The filled circles denote samples for which an additional $2.25 \mathrm{mmol} \mathrm{kg}{ }^{-1} \mathrm{PO}_{4}-\mathrm{P}$ had been added. 


\section{Results}

\section{1. $p H$-dependent vanadium sorption and the influence of $P$}

The sorption of vanadium increased with decreasing $\mathrm{pH}$ for the seven investigated soils (Fig.

1). Only in one soil, Zwijnaarde, was a sorption maximum observed, at $\mathrm{pH}$ 3.6. These observations are comparable to those made by Mikkonen and Tummavuori (1994), who observed maximum $\mathrm{V}$ sorption at around $\mathrm{pH} 4$ for three Finnish soils. Maximum $\mathrm{V}$ sorption at around pH 4 was observed also by Dijkstra et al. (2009) for four of five Dutch polluted soils. The shape of the $\mathrm{pH}$-dependence curves indicates that vanadate(V) rather than vanadyl(IV) was the adsorbing ion, as vanadyl(IV), being a cation, would be expected to sorb more weakly at lower $\mathrm{pH}$, as observed for acid organic soils (Gustafsson et al. 2007).

The results also show that the effect of competing $\mathrm{PO}_{4}-\mathrm{P}$ on the solubility of $\mathrm{V}$ was rather small. In the Säby, Zwijnaarde, Kungsängen A3 and D3 soils, added $\mathrm{PO}_{4}-\mathrm{P}$ caused less than 5 $\%$ reduction in $\mathrm{V}$ sorption. The effect of long-term $\mathrm{P}$ fertilization (for the Kungsängen soil) did not influence the results much, although a slight increase in V solubility was observed in the $\mathrm{D} 3$ treatment. The added $\mathrm{PO}_{4}-\mathrm{P}$ did, however, lead to a large increase in dissolved $\mathrm{PO}_{4}-\mathrm{P}$ (Fig. A1, Associated content). 

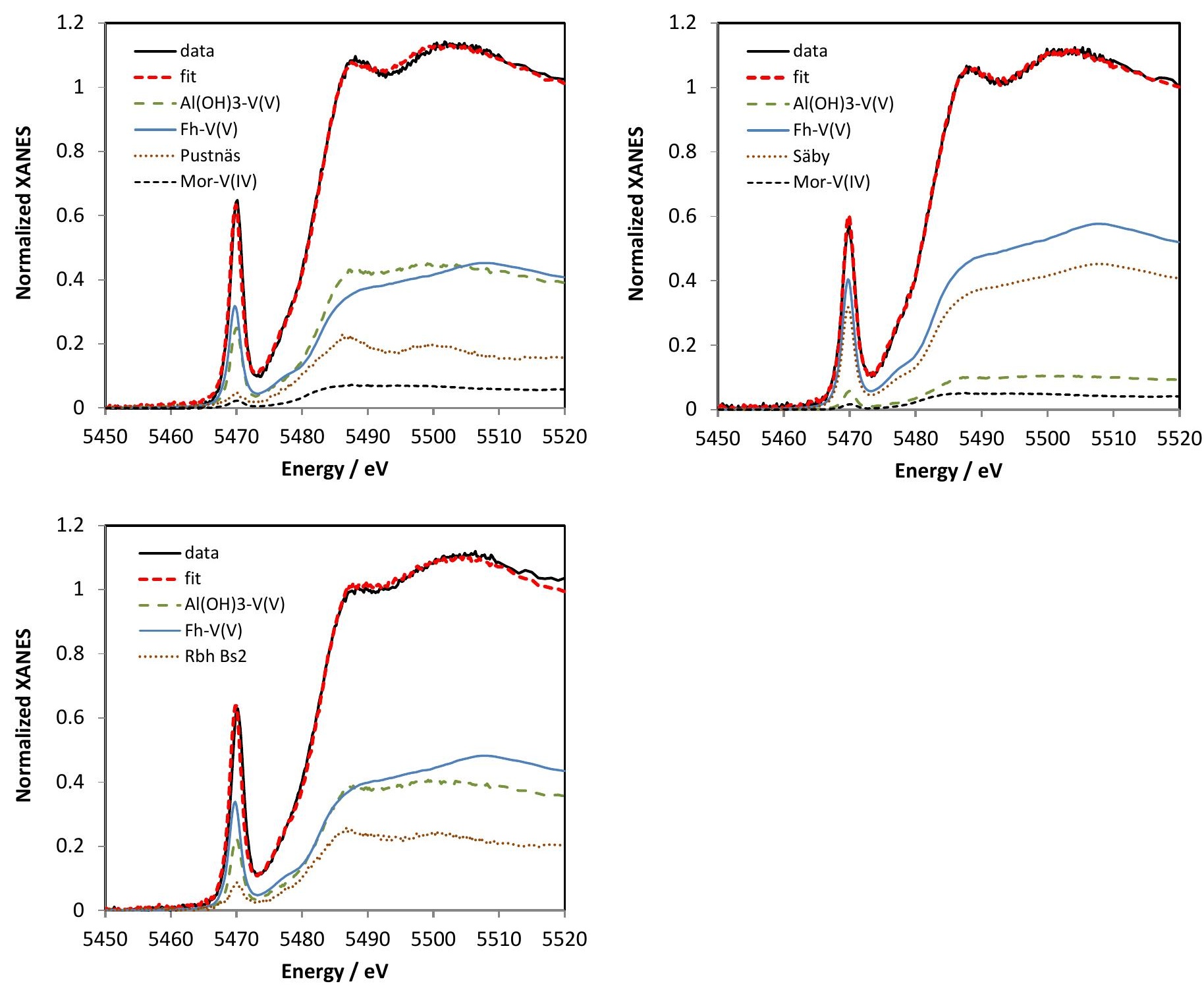

Fig. 2. Linear combination fitting results for three soil samples to which $2.25 \mathrm{mmol} \mathrm{kg}{ }^{-1}$ vanadate $(\mathrm{V})$ had been added. The spectrum for the unamended sample was used as a standard in the fit (dotted line).

\subsection{Freundlich modelling}

For the seven soils for which $\mathrm{pH}$-dependent $\mathrm{V}$ solubility was studied, the fitted $\eta$ values ranged from 0.29 to 0.43 (data not shown), with a mean of 0.36 . When the model was refitted using $\eta=0.36$, reasonable model fits to $\mathrm{pH}$-dependent $[\mathrm{V}]$ were obtained for all seven soils (Fig. 3). Having fixed $\eta$, the Freundlich sorption parameters $Q_{\text {ini }}, K_{\mathrm{F}}$ and $m$ could be optimized 
for all 26 soils (Table 2). In 20 of the 26 soils the model fits were excellent, with $r^{2}>0.99$. The optimised values of $Q_{\text {ini }}$ were, on average, $27 \%$ of the pseudo-total V content (median value: $13.8 \%$ ). This means that part of the originally present $\mathrm{V}$ is adsorbed vanadate( $\mathrm{V})$. For the Pustnäs, Risbergshöjden and Säby soils (which were analysed by XANES spectroscopy), $Q_{\text {ini }}$ was $6.8,34.5$ and $29.0 \%$, respectively, of pseudo-total V.

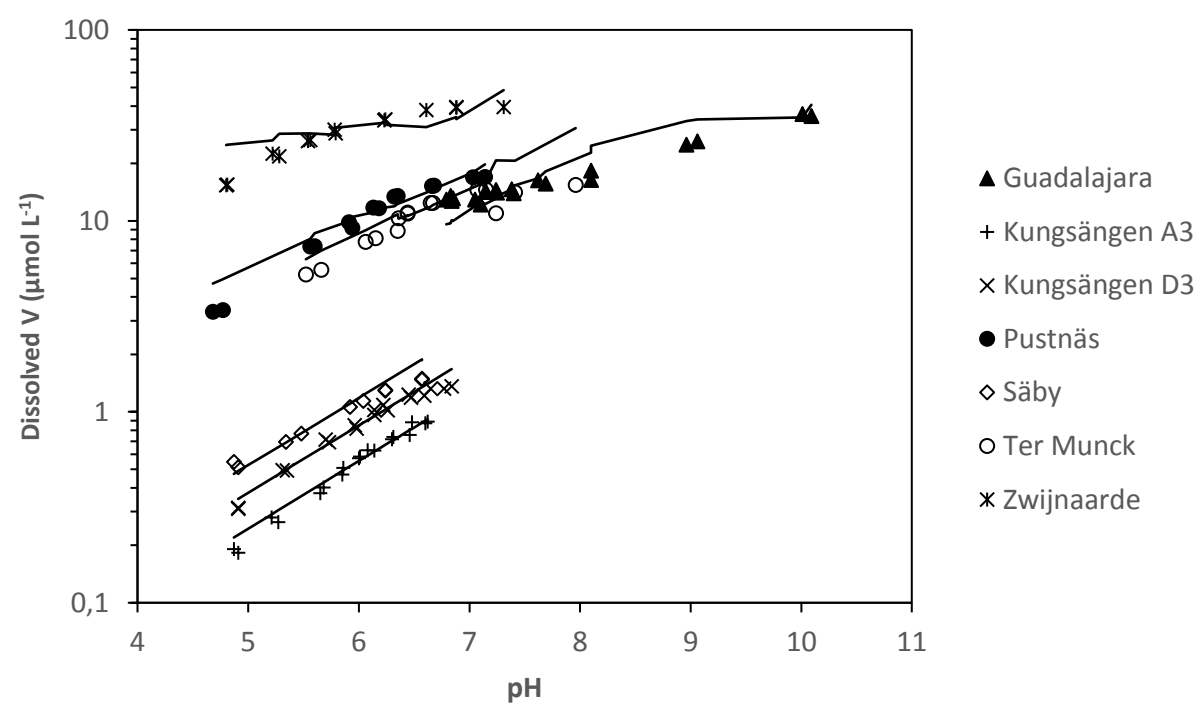

Fig. 3. Dissolved V as a function of $\mathrm{pH}$ for seven soils, after the addition of $150 \mu \mathrm{mol} \mathrm{L} \mathrm{L}^{-1}$ vanadate $(V)$. The symbols represent observations whereas the lines are Freundlich model fits with $\eta=0.36$.

All isotherm model fits are shown in Fig. 4. In the graph, the isotherms are divided into three groups based on the oxalate-extractable $\mathrm{Fe}\left(\mathrm{Fe}_{\mathrm{ox}}\right)$ and $\mathrm{Al}\left(\mathrm{Al}_{\mathrm{ox}}\right)$ content. Although the isotherm groups are not completely separated, the results nevertheless suggest that the content of Fe and $\mathrm{Al}$ hydrous oxides is important for governing the adsorption behaviour of added vanadate(V). A perfect separation would not have been expected anyway, as the oxalateextractable $\mathrm{Fe}$ and $\mathrm{Al}$ pools partly consist of organic matter complexes and as the competition with other anions (e.g. P, Si) may be different in different soils. 


\section{Table 2}

Optimized values for coefficients of the Freundlich equation, and $K_{\mathrm{dS}}$ values for all 26 soils.

\begin{tabular}{lcccccc}
\hline Soil & $\log K_{\mathrm{F}}$ & $m$ & $\begin{array}{c}Q_{\text {ini }} \\
\left(\mathrm{mmol} \mathrm{kg}^{-1}\right)\end{array}$ & $\mathrm{r}^{2}$ & $\begin{array}{c}K_{\mathrm{dS}}, \mathrm{no} \\
\text { added V }\end{array}$ & $\begin{array}{c}K_{\mathrm{dS}}, 10 \mathrm{mg} \mathrm{kg}^{-1} \\
\text { added V }\end{array}$ \\
\hline Bjertorp & 0.750 & 0.469 & 0.085 & 0.999 & 114000 & 11000 \\
E4 & 1.283 & 0.578 & 0.08 & 0.978 & 5100 & 770 \\
Fors A & 0.592 & 0.463 & 0.235 & 0.996 & 1400 & 500 \\
Fors B & 0.227 & 0.422 & 0.11 & 0.992 & 3900 & 470 \\
Guadalajara & 2.006 & 0.704 & 0.008 & 0.980 & 5100 & 82 \\
Hässlen & 1.206 & 0.572 & 0.02 & 1.000 & 103000 & 2500 \\
Högåsa & 0.679 & 0.507 & 0.06 & 0.999 & 8100 & 730 \\
Kloten Bhs & 2.981 & 0.685 & 0.23 & 0.995 & 53000 & 29000 \\
Kloten Bs & 2.247 & 0.584 & 0.165 & 0.998 & 106000 & 45000 \\
Kloten C & 0.495 & 0.502 & 0.01 & 0.996 & 319000 & 1300 \\
Kungsängen A3 & 1.056 & 0.488 & 0.15 & 0.995 & 32000 & 8800 \\
Kungsängen D3 & 1.011 & 0.491 & 0.195 & 0.994 & 89000 & 18000 \\
Lanna & 0.936 & 0,479 & 0.135 & 0.999 & 56000 & 10000 \\
LD-soil & 0.094 & 0.347 & 0.95 & 0.995 & 5100 & 3300 \\
Lilla Böslid & 1.058 & 0.651 & 0.02 & 0.998 & 690 & 41 \\
Lönnstorp & 1.344 & 0.565 & 0.04 & 1.000 & 15000 & 870 \\
Pustnäs & 0.733 & 0.551 & 0.036 & 0.991 & 7300 & 340 \\
Risbergshöjden Bs & 2.283 & 0.616 & 0.14 & 0.991 & 67000 & 24000 \\
Risfallet & 0.438 & 0.395 & 0.56 & 1.000 & 14000 & 10000 \\
Stadsträdgården & 1.666 & 0.636 & 0.06 & 1.000 & 4200 & 550 \\
Säby & 0.608 & 0.443 & 0.33 & 0.990 & 16000 & 6400 \\
Ter Munck & 0.529 & 0.508 & 0.09 & 0.928 & 3000 & 400 \\
Tärnsjö Bs & -0.648 & 0.296 & 0.345 & 0.976 & 17000 & 5200 \\
Zwijnaarde & 1.273 & 0.714 & 0.05 & 0.968 & 160 & 29 \\
Ålbo & 0.193 & 0.378 & 0.27 & 0.999 & 30000 & 8800 \\
Örbyhus 2 & 3.601 & 0.739 & 0.10 & 0.983 & 430000 & 120000 \\
\hline
\end{tabular}

In risk assessments for contaminated areas, the partitioning coefficient $K_{\mathrm{d}}$ is often used in transport models to assess the migration of a contaminant through an environmental medium. Often the $K_{\mathrm{d}}$ value is defined on the basis of the total $\mathrm{V}$ concentration, as the sorbed $\mathrm{V}$ is hard to determine using conventional extractions (Gäbler et al. 2009; Cappuyns and Swennen, 2014). In this paper we refer to this coefficient as the $K_{\mathrm{dS}}$ value, which is defined as:

$$
K_{\mathrm{dS}}=\frac{\text { Tot-V }}{[\mathrm{V}]}
$$


where Tot-V is the pseudo-total $\mathrm{V}$ in $\mathrm{mg} \mathrm{kg}^{-1}$ (see Table A1, Associated content), and [V] is the dissolved vanadium (in $\mathrm{mg} \mathrm{L}^{-1}$ ) in the batch experiment. The $K_{\mathrm{dS}}$ values were quite variable (Table 2), ranging from 160 to 430000 without any added vanadate(V), and from 29 to 120000 after the addition of $10 \mathrm{mg} \mathrm{V} \mathrm{kg}^{-1}$ as vanadate(V). In part the variation is due to the differences in the content of $\mathrm{Fe}$ and $\mathrm{Al}$ hydrous oxides. As an example, $r^{2}=0.60$ for the relationship between $\log \left(\mathrm{Fe}_{\mathrm{ox}}+\mathrm{Al}_{\mathrm{ox}}\right)$ and $\log K_{\mathrm{dS}}$ after addition of $10 \mathrm{mg} \mathrm{V} \mathrm{kg}{ }^{-1}$. However, differences in the content of primary mineral-bound $\mathrm{V}(\mathrm{IV})$, which contributes to total $\mathrm{V}$ but is essentially unreactive (Larsson et al. 2015b), are probably also important for the $K_{\mathrm{dS}}$ value.

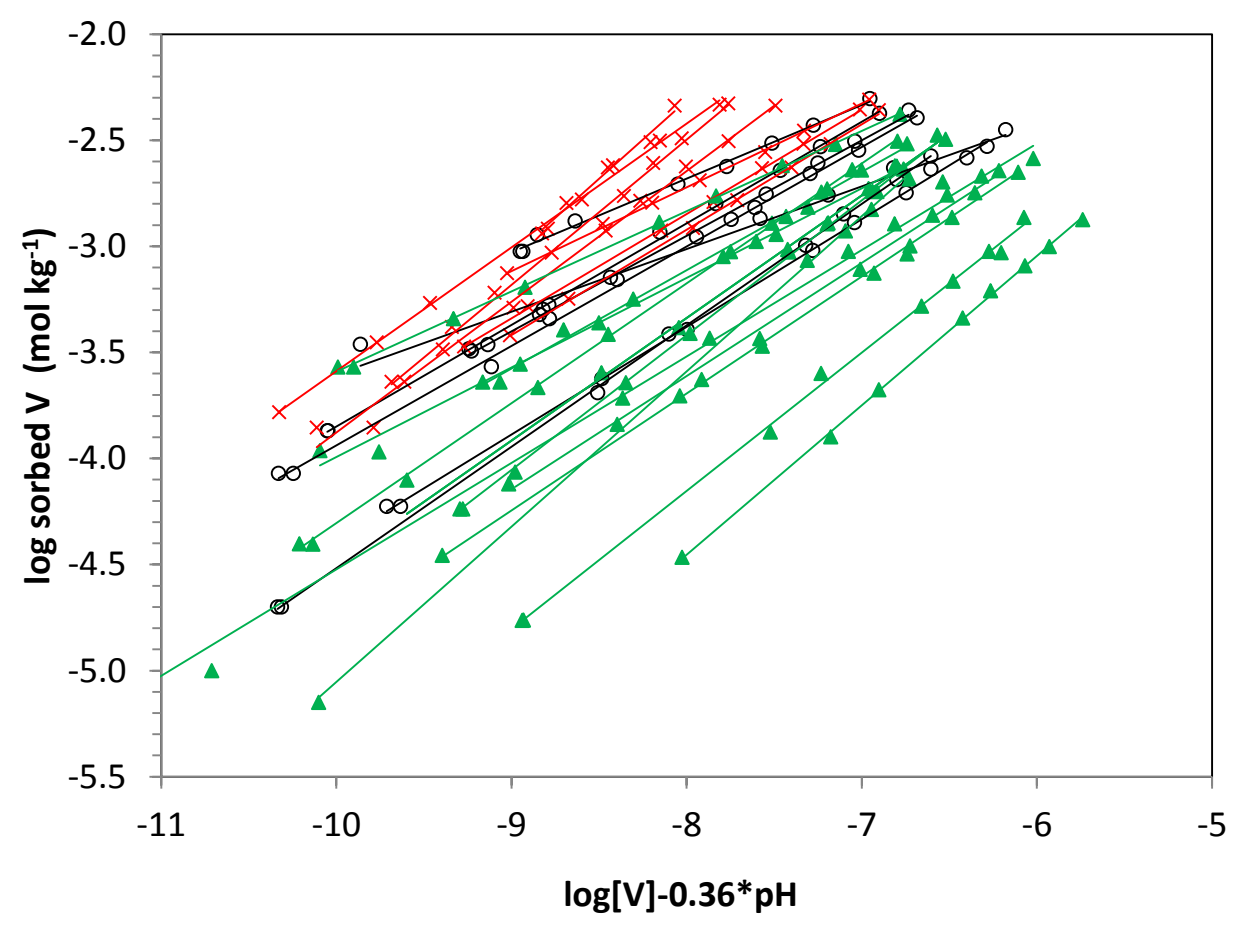

Fig. 4. Amount of sorbed $\mathrm{V}$ as a function of the term $\log [\mathrm{V}]-0.36^{*} \mathrm{pH}$ for all 26 soils of the study. Samples are grouped according to the content of oxalate-extractable Al and Fe content. Red crosses represent samples with $\mathrm{Fe}_{\mathrm{ox}}+\mathrm{Al}_{\mathrm{ox}}>0.2 \mathrm{~mol} \mathrm{~kg}^{-1}$, black circles are soils with $\mathrm{Fe}_{\mathrm{ox}}+\mathrm{Al}_{\mathrm{ox}}$ ranging from 0.1 to $0.2 \mathrm{~mol} \mathrm{~kg}{ }^{-1}$, and green triangles are soils with $\mathrm{Fe}_{\mathrm{ox}}+\mathrm{Al}_{\mathrm{ox}}<0.1$ mol kg-1. Model fits are shown as solid lines. 
An environmentally relevant part of the isotherms is the amount of sorbed $\mathrm{V}$ where $[\mathrm{V}]=2.5$ mg L ${ }^{-1}$, being close to the mean solution EC50 observed by Larsson et al. (2013). This value was termed the FSS ("Freundlich sorption strength") by the latter authors. Here, the modelcalculated FSS values ranged from 27 to $8718 \mathrm{mg} \mathrm{V} \mathrm{kg}^{-1}$ (see Table A1, Associated content), with the largest value recorded for Örbyhus 2, which indicates strong V sorption. However, the Örbyhus 2 soil did not have high contents of oxalate-extractable Fe and Al. Consequently, when plotting $\log \mathrm{FSS}$ as a function of $\log \left(\mathrm{Fe}_{\mathrm{ox}}+\mathrm{Al}_{\mathrm{ox}}\right)$ (Fig. 5), the Örbyhus 2 soil is an outlier. If the Örbyhus 2 soil is removed, a strong relationship is observed $\left(r^{2}=0.85\right)$, as expected if $\mathrm{V}$ binding is dominated by vanadate(V) sorption to $\mathrm{Fe}$ and $\mathrm{Al}$ hydrous oxides.

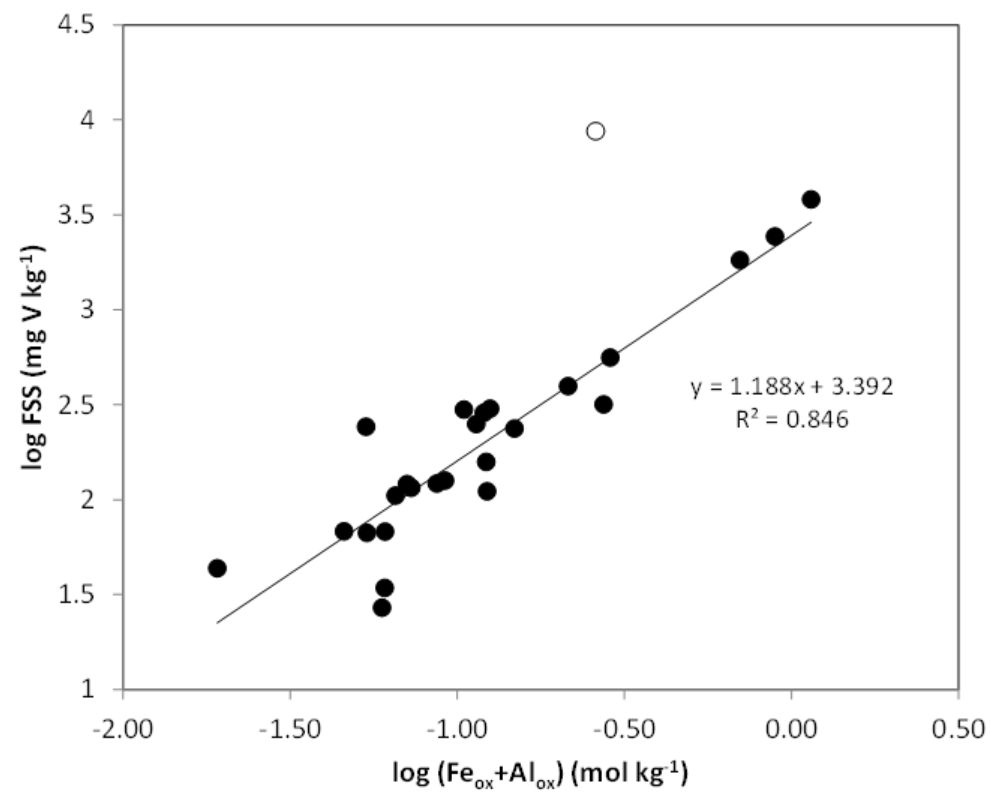

Fig. 5. Log-log relationship between the amount of oxalate-extractable $\mathrm{Fe}$ and $\mathrm{Al}\left(\mathrm{Fe}_{\mathrm{ox}}+\mathrm{Al}_{\mathrm{ox}}\right)$ and the FSS (i.e. the amount of V sorbed at $[\mathrm{V}]=2.5 \mathrm{mg} \mathrm{L}^{-1}$ ). The empty circle, which represents the sample from Örbyhus 2, was removed from the regression (see text).

We hypothesize that there was an important contribution from vanadyl(IV) complexation to organic matter in the Örbyhus 2 soil, as this sample was the most acidic of all 26 samples $\left(\mathrm{pH}\left(\mathrm{H}_{2} \mathrm{O}\right)=4.5\right)$, and as it contained a fairly high content of organic $\mathrm{C}(3.1 \%$; Table $\mathrm{A} 1$, 
Associated content). This may have explained the anomalously strong V sorption in this sample. Unfortunately no XANES data are available for this soil for confirmation.

\section{Discussion}

This paper demonstrates that a Freundlich-based model can describe vanadium sorption to mineral soil samples with reasonable accuracy. This is possible as sorbed vanadate $(\mathrm{V})$ is the most important V species in most mineral soils, with the possible exception of some acidic $(\mathrm{pH} \leq 4.5)$ soils with high organic matter content. For calibration, the model needs no more than three data points from an isotherm experiment with recorded values of $\mathrm{pH}$ and dissolved vanadium.

Our model approach is broadly similar to the one taken by Gäbler et al. (2009). However, the latter authors did not include a $\mathrm{pH}$ term, as their data did not indicate a strong $\mathrm{pH}$ effect. Our data are largely in agreement with this, as the magnitude of the $\mathrm{pH}$ term was small, with 0.36 $\mathrm{H}^{+}$accompanying each vanadate $(\mathrm{V})$ ion during adsorption and desorption. This can be compared to nearly $2 \mathrm{H}^{+}$in the case of $\mathrm{SO}_{4}$ adsorption (Gustafsson et al. 2015). A reason for this difference is probably that the vanadate ion is already diprotonated (i.e. as $\mathrm{H}_{2} \mathrm{VO}_{4}{ }^{-}$) under most conditions of the experiments. However, the $\mathrm{pH}$ term does affect the results to some extent when large variations in $\mathrm{pH}$ exist in the data set.

The finding that $Q_{\mathrm{ini}}$ was on average $27 \%$ of pseudo-total $\mathrm{V}$ means that adsorbed vanadate(V) makes up a substantial fraction of total V in some soils. Of the three soils studied using V Kedge XANES spectroscopy, Pustnäs had the lowest percentage adsorbed vanadate(V), $6.8 \%$. Consistent with this, Pustnäs had also the lowest mean vanadium valence $(+3.7$; Table 1$)$. This suggests that the native $\mathrm{V}$ in mineral soils may consist of several vanadium species, 
including both vanadium(III) and vanadium(IV) bound in primary minerals, as well as adsorbed vanadate(V) and to a minor extent organically complexed vanadyl(IV).

The FSS seems to be an important determinant of the EC50 value for V plant toxicity (Larsson et al. 2013). The Freundlich-based model may be a tool for calculation of the FSS and therefore to relate the soil geochemical properties to EC50.

The Freundlich model was developed for systems in which soil samples had been equilibrated for only $6 \mathrm{~d}$. Probably, the $\mathrm{V}$ sorption will increase with time due to diffusion into micropores of the hydrous oxides - this will not only affect the sorption parameters but also the toxicity (Martin and Kaplan, 1998; Baken et al. 2012). The use of a relatively short equilibration time in the batch experiments may, however, be preferred due to the need for a precautionary approach in risk assessments. Another factor that might affect long-term V sorption is slow redox conversions, e.g. if vanadate(V) is only slowly transformed to vanadyl(IV). However, in a previous paper we showed that the vanadium redox reactions are quick in soils (Larsson et al. 2015b), and for this reason such slow transformations appear unlikely to be significant.

As discussed elsewhere (Larsson et al. 2013; Larsson et al. 2015b) the total V content of a soil is a poor predictor of V toxicity. Cappuyns and Slabbinck (2012) reviewed various risk-based norms for total $\mathrm{V}$ in soil in different European countries. These guidelines range from 42 to $500 \mathrm{mg} \mathrm{V} \mathrm{kg}{ }^{-1}$. They can be directly compared to the FSS values shown in Table A1, Associated content. While in most cases FSS is several hundred $\mathrm{mg} \mathrm{V} \mathrm{kg}^{-1}$, two soils have FSS values lower than $42 \mathrm{mg} \mathrm{V} \mathrm{kg}^{-1}$. Moreover it should be kept in mind that the FSS is defined for $[\mathrm{V}]=2.5 \mathrm{mg} \mathrm{L}^{-1}$, which is likely to be significantly higher than the NOEC value for some organisms. Hence, today's guidelines are not only poorly related to V toxicity, they 
actually also risk to be under-protective as concerns $\mathrm{V}$ toxicity (although the most likely scenario is over-protection, because of the strong contribution from unreactive primary mineral-bound forms of $\mathrm{V}$ to total $\mathrm{V}$ ). This calls for an improved approach for estimating potentially harmful concentrations of $\mathrm{V}$ in the environment. Two alternative approaches likely to be more successful are if: (i) the risk-based values for $\mathrm{V}$ are estimated from dissolved $\mathrm{V}$ in the soil solution, or if (ii) an added risk approach is employed, where a Freundlich-based model can calculate the FSS value, which in turn is used to predict the PNEC value.

\section{Conclusions}

A pH-dependent Freundlich equation was applied for vanadium sorption data from 26 soils. In most cases the equation yielded good fits when the $\mathrm{pH}$ dependence term was set such that $0.36 \mathrm{H}^{+}$accompanied each $\mathrm{H}_{2} \mathrm{VO}_{4}{ }^{-}$ion during adsorption and desorption, which was found to be the average value for seven soils. The use of V K-edge XANES spectroscopy for three selected soils confirmed that adsorbed vanadate $(\mathrm{V})$ was the predominant reaction product for the added vanadate(V). However for the most acidic of the 26 soils formation of complexed vanadium(IV) was likely. The Freundlich sorption strength (i.e. the amount of sorbed vanadium when $[\mathrm{V}]=2.5 \mathrm{mg} \mathrm{L}^{-1}$ ) was strongly related to the sum of oxalate-Fe and oxalate$\mathrm{Al}\left(r^{2}=0.85\right.$ when the acidic soil Örbyhus 2 was excluded $)$, as expected if vanadate(V) adsorption to $\mathrm{Fe}$ and $\mathrm{Al}$ hydrous oxides dominate vanadium sorption.

\section{Acknowledgements}

This research was funded by the Swedish Steel AB Merox. Use of the Stanford Synchrotron

Radiation Lightsource, SLAC National Accelerator Laboratory, is supported by the U.S.

Department of Energy, Office of Science, Office of Basic Energy Sciences under Contract

No. DE-AC02-76SF00515. The SSRL Structural Molecular Biology Program is supported by 
the DOE Office of Biological and Environmental Research, and by the National Institutes of Health, National Institute of General Medical Sciences (including P41GM103393). The contents of this publication are solely the responsibility of the authors and do not necessarily represent the official views of NIGMS or NIH. The authors thank Gunnar Börjesson, Ann Kristin Eriksson and Charlotta Tiberg for supplying some of the soil samples.

\section{References}

Baken, S., Larsson, M.A., Gustafsson, J.P., Cubadda, F., Smolders, E., 2012. Ageing of vanadium in soils and consequences for bioavailability. Eur. J. Soil Sci. 63, 839-847.

Blackmore, D.P.T., Ellis, J., Riley, P.J., 1996. Treatment of a vanadium-containing effluent by adsorption/coprecipitation with iron oxyhydroxide. Wat. Res. 30, 2512-2516.

Brinza, L., Benning, L.G., Statham, P.J., 2008. Adsorption studies of Mo and V onto ferrihydrite. Miner. Mag. 72, 385-388.

Burke, I.T, Peacock, C.L., Lockwood, C.L., Stewart, D.I., Mortimer, R.J.G., Ward, M.B., Renforth, P., Gruiz, K., Mayes, W.M., 2013. Behavior of aluminum, arsenic, and vanadium during the neutralization of red mud leachate by $\mathrm{HCl}$, gypsum, or seawater. Environ. Sci. Technol. 47, 65276535.

Cappuyns, V., Slabbinck, E., 2012. Occurrence of vanadium in Belgian and European alluvial soils. Appl. Environ. Soil Sci. 979501.

Cappuyns, V., Swennen, R., 2014. Release of vanadium from oxidized sediments: insights from different extraction and leaching procedures. Environ. Sci. Pollut. Res. 21, 2272-2282.

Dijkstra, J.J., Meeussen, J.C.L., Comans, R.N.J., 2009. Evaluation of a generic multisorption model for inorganic soil contaminants. Environ. Sci. Technol. 43, 6196-6201.

Eriksson, A.K., Gustafsson, J.P., Hesterberg, D., 2015. Phosphorus speciation of clay fractions from long-term fertility experiments in Sweden. Geoderma 214-242, 68-74.

Eriksson, A.K., Hesterberg, D., Klysubun, W., Gustafsson, J.P., 2016. Phosphorus dynamics in Swedish agricultural soils as influenced by fertilization and mineralogical properties: Insights gained from batch experiments and XANES spectroscopy. Sci. Total Environ. 566-567, 1410-1419.

Groenenberg, J.E., Dijkstra, J.J., Bonten, L.T.C, de Vries, W., Comans, R.N.J., 2012. Evaluation of the performance and limitations of empirical partition-relations and process based multisurface models to predict trace element solubility in soils. Environ. Pollut. 166, 98-107. 
Gustafsson, J.P., 2006. Arsenate adsorption to soils: modeling the competition from humic substances. Geoderma 136, 320-330.

Gustafsson, J.P., Persson, I., Kleja, D.B., van Schaik, J.W.J., 2007. Binding of iron(III) to organic soils: EXAFS spectroscopy and chemical equilibrium modeling. Environ. Sci. Technol. 41, 12321237.

Gustafsson, J.P., Akram, M., Tiberg, C., 2015. Predicting sulphate adsorption/desorption in forest soils: evaluation of an extended Freundlich equation. Chemosphere 119, 83-89.

Gäbler, H.E., Gluh, K., Bahr, A., Utermann, J., 2009. Quantification of vanadium adsorption by German soils. J. Geochem. Explorat. 103, 37-44.

Kaplan, D.I., Sajwan, K.S., Adriano, D.C., Gettier, S., 1990. Phytoavailability and toxicity of beryllium and vanadium. Water Air Soil Pollut. 53, 203-212.

Kelly, S.D., Hesterberg, D., Ravel, B., 2008. Analysis of soils and minerals using X-ray absorption spectroscopy. In: Ulery AL, Drees R (eds) Methods of Soil Analysis - Part 5. Mineralogical methods. Soil Science Society of America, pp 387-464.

Larsson, M.A., Baken, S., Gustafsson, J.P., Hadialhejazi, G., Smolders, E., 2013. Vanadium bioavailability and toxicity to soil microorganisms and plants. Environ. Toxicol. Chem. 32, 2266-2273.

Larsson, M.A., Baken, S., Smolders, E., Cubadda, E., Gustafsson, J.P., 2015a. Vanadium bioavailability in soils amended with blast furnace slag. J. Hazard. Mater. 296, 158-165.

Larsson, M.A., D’Amato, M., Cubadda, F., Raggi, A., Öborn, I., Kleja, D.B., Gustafsson, J.P., 2015b. Long-term fate and transformations of vanadium in a pine forest soil with added converter lime. Geoderma 259-260, 271-278.

Martin, H.W., Kaplan, D.I., 1998. Temporal changes in cadmium, thallium and vanadium mobility in soil and phytoavailability under field conditions. Water Air Soil Pollut. 101, 399-410.

Mikkonen, A., Tummavuori, J., 1994. Retention of vanadium (V) by three Finnish mineral soils. Eur. J. Soil Sci. 45, 361-368.

Peacock, C.L., Sherman, D.M., 2004. Vanadium(V) adsorption onto goethite ( $\alpha-\mathrm{FeOOH})$ at pH 1.5 to 12: A surface complexation model based on ab initio molecular geometries and EXAFS spectroscopy. Geochim. Cosmochim. Acta 68, 1723-1733.

Ravel, B., Newville, M., 2005. ATHENA, ARTEMIS, HEPHAESTUS: data analysis for X-ray absorption spectroscopy using IFEFFIT. J. Synchrotron Rad. 12, 537-541.

Rietra, R.P.J.J., 2001. Relationship between the molecular structure and ion adsorption on goethite. $\mathrm{PhD}$ thesis, Wageningen University, Nederländerna.

Salminen, R., Batista, M.J., Bidovec, M., Demetriades, A., De Vivo, B., De Vos, W., Duris, M., Gilucis, A., Gregorauskiene, V., Halamic, J., Heitzmann, P., Lima, A., Jordan, G., Klaver, G., Klein, P., Lis, J., Locutura, J., Marsina, K., Mazreku, A., O'Connor, P.J., Olsson, S.Å., Ottesen, R.T., Petersell, V., Plant, J.A., Reeder, S., Salpeteur, I., Sandström, H., Siewers, U., Steenfelt, A., 
Tarvainen, T., 2005. Geochemical Atlas of Europe. Part 1: Background Information, Methodology and Maps. Espoo, Geological Survey of Finland.

Sauvé, S., Hendershot, W., Allen, H.E., 2000. Solid-solution partitioning of metals in contaminated soils: dependence on $\mathrm{pH}$, total metal burden, and organic matter. Environ. Sci. Technol. 34, 1125 1131.

Tannazi, F., Bunker, G., 2005. Determination of chemical speciation by XAFS. Physica Scripta T115, 953-956.

Thompson, A., Attwood, D., Gullikson, E., Howells, M., Kim, K.-J., Kirtz, J., Kortright, J., Lindau, I., Liu, Y., Pianetta, P., Robinson, A., Scofield, J., Underwood, J., Williams, G., Winck, H., 2009. X-ray Data Booklet. Lawrence Berkeley National Laboratory, University of California, Berkeley, California.

Wällstedt, T., Björkvald, L., Gustafsson, J.P., 2010. Increasing concentrations of arsenic and vanadium in (southern) Swedish streams. Appl. Geochem. 25, 1162-1175.

Weng, L.P., Vega, F.A., van Riemsdijk, W.H., 2011. Competitive and synergistic effects in pH dependent phosphate adsorption in soils: LCD modeling. Environ. Sci. Technol. 45, 8420-8428. 